\title{
O desafio tropicalista de integrar pesquisa biomédica ao serviço: conhecer, cuidar e vigiar
}

Challenge of tropical doctors to integrate biomedical research in the service: to know, take care and watch over

El desafío tropical de integrar la investigación biomédica al servicio: conocer, cuidar y vigilar

"Agora, em região do extremo norte do Brasil, onde não consta tenha sido verificada
a infecção humana, outro animal silvestre se apresenta com a mesma infecção".

Carlos Chagas, 1924

Em qualquer agravo à saúde humana, os bons profissionais da saúde coletiva, entre executores, gestores e pesquisadores, devem entender sua história desde o início até o momento atual, incluindo todos os processos sociais e políticos que emolduraram as estratégias de prevenção, eliminação ou controle a ela relacionados. Nisso não há qualquer novidade. A novidade está no fato de que essas estratégias devem ser formuladas hoje como políticas públicas de potencial aplicabilidade prática e em curtíssimo prazo, em consonância com nossas rápidas e disponíveis tecnologias digitais.

Focando na doença de Chagas na Amazônia, mas sem discorrer sobre toda sua longa história, vejamos, em um salto de quase 100 anos, dois de seus tempos-processos iniciais e atuais modeladores das estratégias de controle. As primeiras evidências da presença da doença de Chagas na Amazônia brasileira aconteceram em 1924, quando o médico e pesquisador Jayme Aben-Athar, ao estudar macacos-prego, encontrou alguns parasitos no sangue desses animais e, na dúvida, enviou-os ao dr. Carlos Chagas, que corroborou seu achado como sendo Trypanosoma'. Evidências sequenciais marcaram o pioneirismo de pesquisadores locais, com estudos relativos aos ciclos peridomiciliares do Trypanosoma cruzi e culminaram no registro dos primeiros casos humanos com características regionais de transmissão oral em 19692,3,4,5,6.

Cerca de 100 anos após a descoberta da doença no Brasil e aproximadamente 50 anos depois dos primeiros registros amazônicos de casos, temos alguns sucessos e muitos desafios em perspectiva. Alcançado em 2006, o controle da transmissão domiciliar da principal espécie, o Triatoma infestans, está hoje ameaçado pelo fato de que outros insetos com hábitos peridomiciliares sinalizam substituí-lo7,8,9. Como desafios, citamos os fenômenos epidemiológicos insólitos de outras formas de transmissão, confundindo, sobressaindo e, por vezes, ocultando a clássica transmissão vetorial, obrigando-nos a rápidas redefinições das estratégias de controle e à criação de outras ${ }^{10,11}$.

Se cerca de 100 anos é muito tempo e não nos permite comemorar, os quase 50 anos de doença de Chagas na Amazônia, também não. Nesta região, há cerca de meio século, a ação antrópica invasiva dos espaços naturais de insetos transmissores da doença de Chagas e a existência indubitável do ciclo natural parasitário na região ditam as regras epidemiológicas de sua transmissão.

Para essa doença ou qualquer outra endemia, nosso triunfo como pesquisa integrada ao serviço será o de diminuir cada vez mais o tempo entre a formulação de políticas públicas baseadas em evidências utilizadoras do método científico e a sua aplicação nos modelos atuais de atenção à saúde humana. Ou ainda, como os sanitaristas do passado e contemporâneos tropicalistas nos ensinariam: cuidar com rapidez para o benefício dos afetados ou pessoas sob maior risco; mas, essencialmente conhecer, vigiar e prevenir para o benefício de todos.

Ana Yecê das Neves Pinto

Editora Associada da Rev Pan-Amaz Saude

Instituto Evandro Chagas/SVS/MS, Ananindeua, Pará, Brasil 


\section{REFERÊNCIAS}

1 Chagas C. Sobre a verificação do "Trypanosoma cruzi" em macacos do Pará (Chrysothrix sciureus). Scien Med. 1924;2:75-7.

2 Deane MP. Ocorrência do Trypanosoma conorrhini em "barbeiros" e em rato na cidade de Belém, Pará, seu cultivo em meio de NNN. Rev Serv Espec Saude Pub. 1947; 1 (2):433-48.

3 Deane LM. Inquérito de toxoplasmose e de tripanosomíase realizado em Cachoeira do Arari, Ilha do Marajó, Pará, pela V Bandeira Científica do Centro Acadêmico "Oswaldo Cruz" da Faculdade de Medicina da Universidade de S. Paulo. Rev Med. 1964;48(3):107-16.

4 Deane LM. Animal reservoirs of Trypanosoma cruzi in Brazil. Rev Bras Malariol Doencas Trop. 1964 Jan-Mar; 16:27-48.

5 Deane LM. Tripanosomídeos de mamíferos da Região Amazônica III. Hemoscopia e xenodiagnóstico de animais silvestres dos arredores de Belém, Pará. Rev Inst Med Trop S Paulo. 1964;6(5):225-32.

6 Shaw JJ, Lainson R, Fraiha H. Considerações sobre a epidemiologia dos primeiros casos autóctones de doença de Chagas registrados em Belém, Pará, Brasil. Rev Saude Publica. 1969 dez;3(2):153-7.

7 Almeida FB. Triatomíneos da Amazônia. Encontro de três espécies naturalmente infectadas por Trypanosoma semelhante ao cruzi, no Estado do Amazonas (Hemiptera-Reduviidae). Acta Amazon. 1971;1 (1):89-93.

8 Luitgards-Moura JF, Vargas AB, Almeida CE, Magno-Esperança G, Agapito-Souza R, Folly-Ramos E, et al. A Triatoma maculata (Hemiptera, Reduviidae, Triatominae) population from Roraima, Amazon region, Brazil, has some characteristics of a potential Chagas disease vector. Rev Inst Med Trop S Paulo. 2005 May-Jun;47(3):131-7.

9 Ramos Jr AN, Carvalho DM. Os diferentes significados da certificação conferida ao Brasil como estando livre da doença de Chagas. Cad Saude Publica. 2001 nov-dez;17(6):1406-12.

10 Valente SAS, Valente VC, Pinto AYN. Epidemiologia e transmissão oral da doença de Chagas na Amazônia brasileira. In: Organización Panamericana de la Salud. Unidad Regional de Prevention y Control de Enfermedades Transmisibles (DPC/CD/CHA), Grupo Técnico Especializado en inocuidad de Alimentos. Informe de la consulta técnica en Epidemiologia, Prevención y Manejo de la transmisión de la Enfermedad de Chagas como Enfermedad Transmitida por Alimentos (ETA); 2006 may 4-5. Rio de Janeiro: Organización Panamericana de la Salud; 2006. $46 \mathrm{p}$.

11 Valente SAS, Valente VC, Pinto AYN, César MJB, Santos MP, Miranda COS, et al. Analysis of an acute Chagas disease outbreak in the Brazilian Amazon: human cases, triatomines, reservoir mammals and parasites. Trans $R$ Soc Trop Med Hyg. 2009 Mar;103(3):291-7. 